\title{
Self-Regulated Learning in Flipped Classrooms: A Systematic Literature Review
}

\author{
Rasheed Abubakar Rasheed, Amirrudin Kamsin, Nor Aniza Abdullah, Habeebah Adamu Kakudi, \\ Auwal Shehu Ali, Ahmad Sanda Musa, and Adamu Sani Yahaya
}

\begin{abstract}
The flipped classroom is considered an instructional strategy and a type of blended learning instruction that focused on active learning and student engagement. Over the years, flipped classroom studies have focused more on the advantages and challenges of flipped instruction and its effectiveness, but little is known about the state of self-regulation in flipped classrooms. This study investigates the self-regulation strategies as well as the supports proposed for self-regulated learning in flipped classrooms. Findings show that relatively few studies have focused on self-regulated learning in flipped classrooms compared to the overall research and publication productivity in flipped classrooms. Also, the existing solutions and supports have only focused on either self-regulation or online help-seeking, but have not focused on other specific types of self-regulation strategies. Our study proposed some future research recommendations in flipped classrooms.
\end{abstract}

Index Terms-Blended learning, flipped classrooms, self-regulation.

\section{INTRODUCTION}

The flipped classroom is considered an instructional strategy and a type of blended learning instruction that focused on active learning and student engagement. Flipped learning has recently received a great deal of attention [1], [2] and has arguably become the 'new norm' type of blended learning. Students in the flipped classrooms are assumed to be responsible for their own learning, at their own pace, prior to their face-to-face classes [3], [4].

Teachers in flipped classrooms act as facilitators of the in-class group discussions, to support and answer students' questions, guide and facilitate the students towards ensuring that students learn from different perspectives, rather than transmitting knowledge directly [3], [5]. Flipped classrooms are also known as inverted classrooms, 24/7 classroom and reverse instruction due to reversal of the learning activities from the typical blended learning instruction [1]. As such, flipped classroom online component involves pre-class online-based individual learning; and the face-to-face component involves in-class interactive group learning [6].

Manuscript received January 21, 2020; revised March 18, 2020. This work was supported by the Interdisciplinary Research Programme Grant (IIRG) under project IIRG031B-2019 (University of Malaya).

Rasheed Abubakar Rasheed, Amirrudin Kamsin, Nor Aniza Abdullah, and Habeebah Adamu Kakudi are with Faculty of Computer Science and Information Technology, University of Malaya, 50603 Kuala Lumpur Malaysia (e-mail: rasheediman@gail.com, amir@um.edu.my, noraniza@um.edu.my, habeebahkakudi@gmail.com).

Auwal Shehu Ali, Ahmad Sanda Musa, and Adamu Sani Yahaya are with the Faculty of Computer Science and Information Technology, Bayero University Kano, Nigeria (e-mail: asali@gmail.com, asyahaya.it@buk.edu.ng).
This rational behind flipped learning is to maximize the face-to- face in-class for teacher-student interaction and to provide students with personalized feedback on their learning [1], [7]. Flipped classrooms enables students to engage and participate within themselves as well as in-group learning activities.

Flipped classroom type of blended learning involves students in learning activities both in the face-to-face and online components [8]. With every technology mediated instruction, the online component (pre-class learning activities as the case of flipped classrooms) are critical for the success of the flipped type, as students must adequately be prepared for prolific participation in the face-to-face session [9]. Normally, students are required to watch the online videos assigned prior to attending the face-to-face classes where they engage in group activities and discussions with their peers as well as the teacher [8].

Several and diverse sets of review studies have been conducted on flipped classrooms e.g. [8], [10]-[13] Since research in blended learning has shown that students' level of success lies in their ability to adopt the necessary self-regulation strategy, it becomes important to understand the exiting solutions, the efforts and the type of solutions that researchers have been offering for improving self-regulation behavior in blended learning environments. Self-regulation is critical for all technology-mediated instructions and in particular flipped classroom success due to the online component and the support or complement that each of these two components offer to one another [14]. Although numerous studies have highlighted or reported on self-regulation [3], [4]. Similarly, other reviews have focused on the advantages and challenges of flipped instruction [2], the effectiveness of flipped classrooms and recommendation of practice in various disciplines [15]-[20], but the flipped classroom literature is short in providing a clear picture of the aspect of self-regulation. As such, this study aims to investigate self-regulated learning in flipped classrooms. This study intends to provide an overview of the current state of students' self-regulation in the flipped classrooms type of blended learning, what self-regulation strategies have been investigated and what supports or approaches have been proposed for improving self-regulation in flipped classrooms as well as the limitation of these approaches.

\section{BACKGROUND}

Self-regulated learning is defined as "an active, constructive process whereby learners set goals for their learning and then attempt to monitor, regulate and control their cognition, intentions and behavior, guided and 
constrained by their goals and the contextual features of the environment"'[20]. Over the years, self-regulation have been researched and researchers have come up with various self-regulated learning models (e.g. see [21]-[24]). [25] classified self-regulated learning strategies into motivation/affect, cognition context areas and behavior areas. Motivational regulation includes intrinsic and extrinsic goal orientation, self-efficacy, control belief, and text anxiety. Cognitive and metacognitive regulation involves elaboration, rehearsal, monitoring, organization, critical thinking and planning, goal setting and task analysis. Behavioral and contextual regulation involves time and study environment, peer learning, effort regulation and help seeking.

In blended learning as well as its derivative - flipped classrooms, students are required to self-regulate their studying activities in their online component sessions. In flipped classrooms, students are expected to engage in active learning and preparedness before the face-to-face classes [26]. Yet, students are fond of devoting relatively less time and adopting undesirable self-regulation strategies in this component. Students are found to procrastinate their study activities until the last moments or deadline. Self-regulated learning involves the regulation of one's emotion, cognitive behavior and adopting the necessary and desirable skills suitable for a learning experience. Students that can monitor and regulate their moods, feelings and emotions would be in a better position to control his/her behavior and consequently their studying in online environments and would less likely succumb to undesirable behavior such as procrastination [27] For instance, students' self-regulation behavior in pre class component (online component of blended learning) of flipped classroom involves adopting the necessary online learning strategies and scaffolds such as online help-seeking, proper time management, the ability to actively monitor emotional states such as frustration, online discussions, reading study materials promptly and not procrastinating study tasks till deadlines.

\section{Methodology}

The following research questions were investigated for in this study:

1) What self-regulation strategies have been investigated in flipped classrooms?

2) What supports have been proposed to improve self-regulation in flipped classrooms?

\section{A. Literature Search}

Our literature search was conducted in three stages. The first is to query the Web of Science database which is the gateway for social science citation indexed articles (SSCI) and science citation indexed (SCI). We adopted the search string "(blend* learning OR hybrid learning OR flipped learning OR blend* course OR hybrid course OR flipped course OR flipped classroom *)" adopted from the influential studies of blended learning [14], [28], [29] which was keyed into the advanced search option of Web of Science database. The year range was specified from 2010 to 2019; furthermore, articles were refined further by selecting social science citation index (SSCI); and research area (Educational Education Research, educational psychology research and educational scientific discipline) by adopting a similar method of refinement from [2], [28], [29]. 1002 results were obtained. In addition, we examined the titles, keywords and abstracts of all the results focusing on self-regulation or related terms such as (self-regulation, learning strategy, Metacognition, rehearsal, elaboration, critical thinking, time management, effort management, help seeking, procrastination, peer learning, etc.).

Secondly, we also added five studies found from other sources (Science Direct, Google Scholar) that are relevant and that are not found in Web of Science database using search terms "flip" and "invert". The search was conducted using a multiple combination of 'inverted' and 'flipped' with the Boolean operator "OR" for the reason that some authors use the term "inverted classroom" interchangeably with the term "flipped classroom,"

\section{B. Eligibility Criteria}

Third, we further refine our studies by adopting the inclusion and exclusion criteria of the studies of [14], [28]: selecting (a) articles that define flipped classrooms as a combination of face-to-face and online interventions; (b) self-regulation or its derivatives such as help seeking, procrastination etc. in flipped classrooms must be the central topic of the article, or in synergy with a related instructional method e.g. [30]; (c) empirical studies; (d) articles must mainly investigate educational aspects of flipped classrooms in educational settings. The excluded articles involve those that :(a) articles focusing solely on face-to-face aspects of flipped classrooms; (b) book chapter reviews; (c) non-English articles; and (d) articles in which the full text was not available. A total of 14 final studies were finally selected.

\section{RESULTS}

We categorized the results into two: the studies that investigate self-regulation in flipped classrooms, and the studies that proposed solutions for self-regulation in flipped classrooms to answer our research questions.

\section{A. What Self-Regulation Strategies Have Been Investigated in Flipped Classrooms?}

Because, todays education involves the use of technology, self-regulation has been a constant challenge that researchers in various or all online learning instructions are constantly battling with, due to the freedom, flexibility and authority granted to learners in these environments. Researchers have investigated and tried to understand various aspects and types of self-regulated learning in order to offer solutions to combat its negative effect and the drawback it renders to modern education as a whole. From Table I, the study of [6] aims at determining the pedagogical impact of flipped classrooms with reference to self-regulation for enhancing formative learning outcomes. Results of the study shows that students in flipped classroom apply their self-learned knowledge and adopt better self-regulation strategies for their online activities. The study of [31] explores study activities of nursing students studying physiology in a flipped classroom using digital tools of varied dimensions. The study found that nursing students prefer using an external commercial website resource for online materials and studying. 
TABLE I: SELF-REgUlation STRATEGIES THAT HAVE BEEN INVESTIGATED IN FLIPPED CLASSROOMS

\begin{tabular}{|c|c|c|}
\hline Articles & Aim & Results \\
\hline [3] & $\begin{array}{l}\text { To determine whether flipped classroom with } \\
\text { reference to self-regulation principles, is a } \\
\text { good pedagogy for improving formative } \\
\text { learning outcomes }\end{array}$ & $\begin{array}{l}\text { Findings of the study shows students ability to apply their self-learned } \\
\text { knowledge prior to their face-to-face classes. }\end{array}$ \\
\hline$[31]$ & $\begin{array}{l}\text { To explore study activities of students in a } \\
\text { flipped classroom by the use of using various } \\
\text { digital tools }\end{array}$ & $\begin{array}{l}\text { Students were more comfortable using resources from an external commercial } \\
\text { website. As such, this finding could be arguably be related to students' need for } \\
\text { an autonomy; } \\
\text { Results show that nursing students' ability to perform self-regulated learning } \\
\text { could be affected by the adaptation to higher education. Secondly, students } \\
\text { that were able to handle stressful situations and students with high ability to } \\
\text { handle stressful situations looked to adopt more self-regulation strategies for } \\
\text { studying. }\end{array}$ \\
\hline [4] & $\begin{array}{l}\text { To examine the relationships between three } \\
\text { key self-regulatory constructs - 'self-efficacy, } \\
\text { prior domain knowledge and the use of } \\
\text { learning strategies' with academic } \\
\text { achievement }\end{array}$ & $\begin{array}{l}\text { Results show that self-efficacy and online help seeking strategies were } \\
\text { significantly positively related to academic achievement in both the pre-class } \\
\text { and in-class flipped classroom components. } \\
\text { Students' self-efficacy in collaborative learning had a positive impact on their } \\
\text { use of help seeking strategies during in-class learning. }\end{array}$ \\
\hline [32] & $\begin{array}{l}\text { To explore how the self-regulated learning } \\
\text { skills of the students develop in a flipped } \\
\text { learning environment in which problem-based } \\
\text { activities were used. }\end{array}$ & $\begin{array}{l}\text { The goal setting and planning, self-regulated learning, task strategies and help } \\
\text { seeking skills of the students were significantly greater high in in-class } \\
\text { sessions. During the pre-class or online component, goal setting and planning, } \\
\text { environmental structuring skills were significantly high, while time } \\
\text { management, monitoring help seeing, self-evaluation and self-efficacy skills } \\
\text { were moderate while monitoring skills was significantly lower }\end{array}$ \\
\hline [33] & $\begin{array}{l}\text { To improve effective learning and teaching by } \\
\text { investigating the influence of cognitive style, } \\
\text { gender and different teaching strategies in the } \\
\text { flipped classroom }\end{array}$ & $\begin{array}{l}\text { Learning strategy and cognitive style significantly affected students' } \\
\text { satisfaction and learning performance. The peer-learning, interactive video } \\
\text { and social management issues associated with group work improves student's } \\
\text { motivation towards self-regulation }\end{array}$ \\
\hline
\end{tabular}

This was related and understood to students need for an authority. Furthermore, findings show that nursing students' ability to perform self-regulated learning could be affected by the adaptation to higher education. Secondly, students that were able to handle stressful situations and students with high ability to handle stressful situations looked to adopt more self-regulation strategies for studying. The study of examined the relationships between academic achievement and three key self-regulatory constructs - prior domain knowledge, self-efficacy, and the use of learning strategies. Results of the study shows that self-efficacy and online help seeking strategies were significantly positively related to academic achievement in both the pre-class and in-class flipped classroom components. Students' self-efficacy in collaborative learning had a positive impact on their use of help seeking strategies during in-class learning. The study of [32] explore how the self-regulated learning skills of the students develop in a flipped learning environment in which problem based activities were. The study shows that the goal setting and planning, self-regulated learning, task strategies and help seeking skills of the students were significantly greater high in in-class sessions. During the pre-class or online component, goal setting and planning, environmental structuring skills were significantly high, while time management, monitoring help seeing, self-evaluation and self-efficacy skills were moderate while monitoring skills was significantly lower. The study of [33] aimed at promoting more effective teaching and learning in the flipped classroom by the influence of cognitive style, gender and different teaching strategies in the flipped classroom. Findings of the study shows that: Cognitive style and learning strategy significantly affected students' learning performance and satisfaction in both the flipped and revised flipped classrooms; the peer-learning, interactive video and social management issues associated with group work improves students' motivation towards self-regulation.

\section{B. What Supports Have Been Proposed to Improve Self-Regulation in Flipped Classrooms?}

Although flipped classrooms type of blended learning is relatively new and has gradually gained attention, various supports and investigations have been conducted to provide students with a better learning experience through aiding students to proper self-regulate and organize their learning activities in their pre-class components (online), from Table II, the study of [34] designed a flipped learning system to foster students self-regulation behavior and overall academic satisfaction and performance. The approach resulted in improving students overall academic performances compared to normal flipped classrooms as well as equipping student preparedness in their online components and specifically for the face-to-face class sessions. The study of [9] improves students self-regulation behavior in online component by implementing a system consisting of out of class learning system, a self-regulated monitoring system, a teacher management system, and a database. The results of this approach have shown that blended learning students are better self-regulated and tailored their learning activities accordingly. Third, a quasi-experimental design was carried out to investigate the impacts of an 'instant response system' (IRS) on the students' self-regulation, learning achievement, learning satisfaction and self-efficacy.

Findings of the empirical study shows that the learning achievement, self-regulation, self-efficacy and satisfaction of the students who used with the proposed IRS system were significantly better than the students that used the conventional flipped classroom approach. Moreover, in the "environment," "task strategies" and "help seeking" dimensions of self-regulation, the former had significantly higher ratings than the latter [35]. One of the most common approaches that blended learning considered in promoting and improving students online help-seeking initiatives is 
through the use of online discussion boards and text messaging to offer instant help as a form of feedback to students. The study of [36], [37] scaffold students with instant help for pre-class preparation. Furthermore, a web-based help-seeking tool in a flipped classroom was designed by considering some design principles such as teacher support awareness, privacy concerns, peers' help seeking activities and social support promotion has resulted in improving students online help-seeking initiatives [38].

The study of [39] initiated the use of learning analytics for improving students self-regulation which supports students in identifying strategies that can increase their academic performance.

Another notable contribution that blended learning researchers have offered in fostering and scaffolding blended learning students to seek online help is through the use of intelligent tutoring systems. Several studies over the years have adopted the use of intelligent tutoring systems in various domains to monitor support students studying activities in the absence of a teacher - as ITSs mimic the role of a teacher. The study of [40] supports students online help seeking initiatives in flipped classrooms (out of their face-to-face) sessions through intelligent tutoring systems which resulted in positive students' outcomes.

TABLE II: SUPPORTS PROPOSED FOR IMPROVING SELF-REGULATION IN FLIPPED CLASSROOMS

\begin{tabular}{|c|l|l|}
\hline Articles & Challenge focus & \multicolumn{1}{c|}{ Technique/Approach } \\
\hline$[9]$ & Self-regulation & $\begin{array}{l}\text { A system involves: pre-class learning management system, a database, a teacher management system } \\
\text { and a self-regulated monitoring system. }\end{array}$ \\
\hline$[34]$ & Self-regulation & Technology that uses planned instructional strategies with sustainable support for self-regulation \\
\hline$[39]$ & Self-regulation & $\begin{array}{l}\text { Improving self-regulation through the use of learning analytics which supports students in identifying } \\
\text { strategies that can increase their academic performance. }\end{array}$ \\
\hline$[35]$ & Self-regulation & $\begin{array}{l}\text { Using instant response system (IRS)-facilitated collective issue-quest strategy to engage improve } \\
\text { student's self-regulation initiatives in flipped classrooms }\end{array}$ \\
\hline$[38]$ & Online help-seeking & $\begin{array}{l}\text { Online help-seeking system called 'EchoLu' based on four design principles: Student's alertness of } \\
\text { teacher support, promotion of social support, student's needs of privacy in help seeking, improvement } \\
\text { of observability peers' help seeking activities }\end{array}$ \\
\hline$[36]$ & Online help-seeking & Using online discussion board for offering instant help \\
\hline$[37]$ & Online help-seeking & Using online discussion board for offering instant help \\
\hline$[40]$ & Online help-seeking & The use of an Intelligent Tutoring System (ITS) for supporting students in programming tasks \\
\hline
\end{tabular}

\section{DISCUSSION}

This study presents a systematic review of self-regulated learning in flipped classrooms. As flipped classrooms is gaining popularity in educational institutions, it becomes imperative to understand students' self-regulated learning in this environment due to countless studies showing the criticality of self-regulation to the success of every technology-mediated instruction.

Our study has found some interesting results, first, we have found that relatively few studies have focused on self-regulated learning in flipped classrooms compared to the overall research and publication productivity in flipped classrooms. This might be as a result of flipped classrooms been a new type of blended learning and is yet to be fully understood, and also researchers feel that flipped classroom is an active learning type of blended learning and therefore self-regulation is not as critical as in the default blended learning environment. As such, more research is warranted on self-regulated learning in flipped classrooms.

Our study also found that the existing solutions for improving students' self-regulation in flipped classrooms are characterized with offering a generalized solution of improving students' self-regulation behavior. These solutions are limited in targeting individuals' characteristics so as to offer an even better individualized or personalized self-regulation support, keeping in mind that the nature of today's academic institutions and blended learning courses comprises of varied and diverse range and sets of students from different backgrounds, culture, ethnicity and race. Therefore, research is warranted to provide better students self-regulation support on an individual basis such as through the use of social identity groupings.

Our study has found that the existing solutions found have only focused on either self-regulation or online help-seeking self-regulation strategy in improving overall self-regulated learning, but have not specifically consider other specific types of self-regulation strategies such as self-control, time management, online peer-learning, critical thinking, procrastination etc. Numerous influential studies over the years have pointed and signified the importance of other specific types of self-regulation strategies in ensuring students' adoption of the overall self-regulation skills package for the optimization and of the online component of blended learning as a whole.

Existing blended learning literature have stressed the importance of online peer-learning self-regulation strategy due to the sizeable disparity of students in today's modern blended learning educational institutions, as well as the reaping benefits associated with it. These studies also highlighted the underutilization of online peer learning self-regulation strategy. The study of [30] highlighted that online peer learning and help seeking self-regulation are underutilized strategies in blended learning. In order to be able to advance in our investigations of which support in blended learning is best for learners, we need solutions to these types of specific problems that researchers have failed to offer. As such, future research should focus on initiating an online peer-learning self-regulation strategy approach in flipped classrooms to better support flipped learners in their online components. Furthermore, we have found only one study that proposed an approach of detecting students' procrastination behavior in the blended learning type (not flipped classrooms), as procrastination behavior is largely researched in the medical and psychological domain [41], and therefore is less researched in technologically mediated environments such as blended learning. As such, flipped classroom researchers should refocus their attention on investigating and providing additional interventions to dysfunctional behavior particularly procrastination 
specifically to the flipped classroom. Furthermore, e-learning researchers have recently begun to use negotiation mechanisms [42] towards promoting online help-seeking through negotiation mechanisms due to the confirmation that negotiation between students and system improves students' metacognition [43]-[45]. Therefore, research is warranted to investigate the use of negotiation mechanisms in supporting online help-seeking through negotiation systems particularly in flipped classrooms.

One of the limitations of this study is that it only considered studies that are deemed as high impact, with the adoption of a rich inclusion and exclusion criteria framework. There might be other studies that were excluded which would have provided more insights into self-regulated learning in flipped classrooms or might have affected our overall results or conclusion, nevertheless, we strongly feel that our study has offered the basis and laid a strong foundation on research pertaining self-regulation in flipped classroom type of blended learning

In conclusion our study contributes to the blended learning literature in identifying the research gaps and challenges that were not addressed in the flipped classrooms type in order to refocus blended learning researchers towards these important aspects worth pursuing.

\section{CONFLICT OF INTEREST}

The authors declare that they have no known competing financial interests or personal relationships that could have appeared to influence the work reported in this paper.

\section{AUTHOR CONTRIBUTIONS}

Conceptualization: Rasheed Abubakar Rasheed; Methodology: Rasheed Abubakar Rasheed, Amirrudin Kamsin, Nor Aniza Abdullah; Funding: Rasheed Abubakar Rasheed, Amirrudin Kamsin, Nor Aniza Abdullah; Supervision: Amirrudin Kamsin, Nor Aniza Abdullah, Habeebah Adamu Kakudi; Writing - original draft: Rasheed Abubakar Rasheed; Writing - review \& editing: Rasheed Abubakar Rasheed, Auwal Shehu Ali, Ahmad Sanda Musa, Adamu Sani Yahaya.

\section{REFERENCES}

[1] J. Bergmann and A. Sams, Flip Your Classroom: Reach Every Student in Every Class Every Day, International Society for Technology in Education, 2012

[2] G. Akçayır and M. Akçayır, "The flipped classroom: A review of its advantages and challenges," Computers \& Education, vol. 126, pp. 334-345, 2018

[3] E. M. Ng, "Integrating self-regulation principles with flipped classroom pedagogy for first year university students," Computers \& Education, vol. 126, pp. 65-74, 2018.

[4] Z. Sun, K. Xie, and L. H. Anderman, "The role of self-regulated learning in students' success in flipped undergraduate math courses," The Internet and Higher Education, vol. 36, pp. 41-53, 2018.

[5] P. Baepler, J. Walker, and M. Driessen, "It's not about seat time: Blending, flipping, and efficiency in active learning classrooms," Computers \& Education, vol. 78, pp. 227-236, 2014.

[6] J. L. Bishop and M. A. Verleger, "The flipped classroom: A survey of the research," in Proc. the ASEE National Conference, Atlanta, GA, 2013, vol. 30, no. 9 , pp. 1-18.

[7] C. F. Herreid and N. A. Schiller, "Case studies and the flipped classroom," Journal of College Science Teaching, vol. 42, no. 5, pp. 62-66, 2013.

[8] J. O'Flaherty and C. Phillips, "The use of flipped classrooms in higher education: A scoping review," The Internet and Higher Education, vol. 25 , pp. 85-95, 2015.
[9] C.-L. Lai and G.-J. Hwang, "A self-regulated flipped classroom approach to improving students' learning performance in a mathematics course," Computers \& Education, vol. 100, pp. 126-140, 2016.

[10] W. J. Zuber, "The flipped classroom, a review of the literature," Industrial and Commercial Training, 2016.

[11] F. H. Wang, "On the relationships between behaviors and achievement in technology-mediated flipped classrooms: A two-phase online behavioral PLS-SEM model," Computers \& Education, vol. 142, p. 103653, 2019.

[12] L. R. Murillo-Zamorano, J. Á. L. Sánchez, and A. L. Godoy-Caballero, "How the flipped classroom affects knowledge, skills, and engagement in higher education: Effects on students' satisfaction," Computers \& Education, vol. 141, p. 103608, 2019.

[13] I. T. Awidi and M. Paynter, "The impact of a flipped classroom approach on student learning experience," Computers \& Education, vol. 128, pp. 269-283, 2019.

[14] R. Boelens, B. D. Wever, and M. Voet, "Four key challenges to the design of blended learning: A systematic literature review," Educational Research Review, vol. 22, pp. 1-18, 2017.

[15] S. J. DeLozier and M. G. Rhodes, "Flipped classrooms: a review of key ideas and recommendations for practice," Educational Psychology Review, vol. 29, no. 1, pp. 141-151, 2017.

[16] V. Betihavas, H. Bridgman, R. Kornhaber, and M. Cross, "The evidence for 'flipping out': A systematic review of the flipped classroom in nursing education," Nurse Education Today, vol. 38, pp. 15-21, 2016.

[17] C. K. Lo and K. F. Hew, "A critical review of flipped classroom challenges in K-12 education: Possible solutions and recommendations for future research," Research and Practice in Technology Enhanced Learning, vol. 12, no. 1, p. 4, 2017.

[18] A. Karabulut-Ilgu, N. Jaramillo Cherrez, and C. T. Jahren, "A systematic review of research on the flipped learning method in engineering education," British Journal of Educational Technology, vol. 49, no. 3, pp. 398-411, 2018

[19] J. D. Tune, M. Sturek, and D. P. Basile, "Flipped classroom model improves graduate student performance in cardiovascular, respiratory, and renal physiology," Advances in Physiology Education, vol. 37, no 4, pp. 316-320, 2013.

[20] P. R. Pintrich, "The role of goal orientation in self-regulated learning," in Handbook of Self-Regulation, Elsevier, 2000, pp. 451-502.

[21] B. J. Zimmerman, "Attaining self-regulation: A social cognitive perspective," in Handbook of Self-Regulation, Elsevier, 2000, pp 13-39.

[22] D. H. Schunk, "Social cognitive theory and self-regulated learning," in Self-Regulated Learning and Academic Achievement, Springer, 1989, pp. 83-110.

[23] M. Boekaerts, "Self-regulated learning at the junction of cognition and motivation," European Psychologist, vol. 1, no. 2, p. 100, 1996.

[24] D. L. Butler and P. H. Winne, "Feedback and self-regulated learning: A theoretical synthesis," Review of Educational Research, vol. 65, no. 3, pp. 245-281, 1995.

[25] P. R. Pintrich, A Manual for the Use of the Motivated Strategies for Learning Questionnaire (MSLQ), 1991.

[26] J. Jovanovic, N. Mirriahi, D. Gašević, S. Dawson, and A. Pardo, "Predictive power of regularity of pre-class activities in a flipped classroom," Computers \& Education, vol. 134, pp. 156-168, 2019.

[27] S. Vanslambrouck, C. Zhu, B. Pynoo, K. Lombaerts, J. Tondeur, and R. Scherer, "A latent profile analysis of adult students' online self-regulation in blended learning environments," Computers in Human Behavior, vol. 99, pp. 126-136, 2019.

[28] R. A. Rasheed, A. Kamsin, and N. A. Abdullah, "Challenges in the online component of blended learning: A systematic review," Computers \& Education, vol. 144, p. 103701, 2020.

[29] R. A. Rasheed, A. Kamsin, and N. A. Abdullah, "Students and teachers' challenges of using technology in blended learning environments," in Proc. the 2020 the 3rd International Conference on Computers in Management and Business, 2020, pp. 195-200.

[30] J. Broadbent, "Comparing online and blended learner's self-regulated learning strategies and academic performance," The Internet and Higher Education, vol. 33, pp. 24-32, 2017

[31] H. M. Bingen, S. A. Steindal, R. Krumsvik, and B. Tveit, "Nursing students studying physiology within a flipped classroom, self-regulation and off-campus activities," Nurse Education in Practice, vol. 35 , pp. 55-62, 2019.

[32] Ü. Çakıroğlu and M. Öztürk, "Flipped classroom with problem based activities: Exploring self-regulated learning in a programming language course," Journal of Educational Technology \& Society, vol. 20, no. 1, pp. 337-349, 2017. 
[33] Y.-T. Chen, S. Liou, and L.-F. Chen, "The relationships among gender, cognitive styles, learning strategies, and learning performance in the flipped classroom," International Journal of Human-Computer Interaction, vol. 35, no. 4-5, pp. 395-403, 2019.

[34] W. J. Shyr and C. H. Chen, "Designing a technology-enhanced flipped learning system to facilitate students' self-regulation and performance," Journal of Computer Assisted Learning, vol. 34, no. 1, pp. 53-62, 2018.

[35] P. Y. Chen and G. J. Hwang, "An IRS-facilitated collective issue-quest approach to enhancing students' learning achievement, self-regulation and collective efficacy in flipped classrooms," British Journal of Educational Technology, vol. 50, no. 4, pp. 1996-2013, 2019.

[36] J. M. Fautch, "The flipped classroom for teaching organic chemistry in small classes: Is it effective?" Chemistry Education Research and Practice, vol. 16, no. 1, pp. 179-186, 2015.

[37] B. L. Hardin and D. A. Koppenhaver, "Flipped professional development: An innovation in response to teacher insights," Journal of Adolescent \& Adult Literacy, vol. 60, no. 1, pp. 45-54, 2016.

[38] E. Er, T. J. Kopcha, M. Orey, and W. Dustman, "Exploring college students' online help-seeking behavior in a flipped classroom with a web-based help-seeking tool," Australasian Journal of Educational Technology, vol. 31, no. 5, 2015 .

[39] J. C. S. Silva, E. Zambom, R. L. Rodrigues, J. L. C. Ramos, and F. F. Souza, "Effects of learning analytics on students' self-regulated learning in flipped classroom," International Journal of Information and Communication Technology Education (IJICTE), vol. 14, no. 3, pp. 91-107, 2018.

[40] H. Mohamed and M. Lamia, "Implementing flipped classroom that used an intelligent tutoring system into learning process," Computers \& Education, vol. 124, pp. 62-76, 2018

[41] W. Eerde and K. B. Klingsieck, "Overcoming procrastination? A meta-analysis of intervention studies," Educational Research Review, vol. 25, pp. 73-85, 2018.

[42] C.-Y. Chou, K. R. Lai, P.-Y. Chao, S.-F. Tseng, and T.-Y. Liao, "A negotiation-based adaptive learning system for regulating help-seeking behaviors," Computers \& Education, vol. 126, pp. 115-128, 2018.

[43] C.-Y. Chou, K. R. Lai, P.-Y. Chao, C. H. Lan, and T.-H. Chen, "Negotiation based adaptive learning sequences: Combining adaptivity and adaptability," Computers \& Education, vol. 88, pp. 215-226, 2015.

[44] Z.-H. Chen, H.-D. Lu, and C.-Y. Chou, "Using game-based negotiation mechanism to enhance students' goal setting and regulation," Computers \& Education, vol. 129, pp. 71-81, 2019

[45] C.-H. Lan, S. Graf, K. R. Lai, and K. Kinshuk, "Enrichment of peer assessment with agent negotiation," IEEE Transactions on Learning Technologies, vol. 4, no. 1, pp. 35-46, 2010

Copyright $(2020$ by the authors. This is an open access article distributed under the Creative Commons Attribution License which permits unrestricted use, distribution, and reproduction in any medium, provided the original work is properly cited (CC BY 4.0).

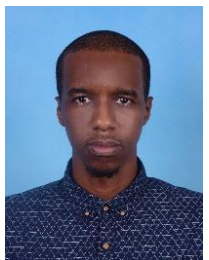

Rasheed Abubakar Rasheed received the B.Sc. in computer science from Bayero University Kano, Nigeria in 2008; the M.Sc. in management information systems from Coventry University UK in 2011; another M.Sc. in software engineering from University of Portsmouth UK in 2015. He is currently a lecturer with the Faculty of Computer Science and Information Technology, Bayero University Kano, and a PhD

student at University of Malaya, Malaysia. His research interests include e-learning, blended learning, personalized and adaptive learning, recommender systems and software verification.

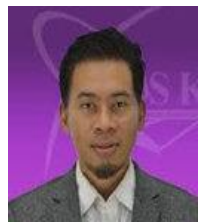

Amirrudin Kamsin is a senior lecturer at the Faculty of Computer Science and Information Technology, University of Malaya, Malaysia. He received his BIT (management) and MSc in computer animation from University of Malaya and Bournemouth University, UK respectively. He obtained his $\mathrm{PhD}$ from University College London (UCL). His research areas include human computer interaction (HCI), authentication systems, e-learning, mobile applications, serious game, augmented reality and mobile health services.

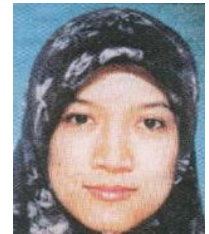

Nor Aniza Abdullah received the bachelor's degree (hons.) in computer science from the University of Malaya, the master's degree in interactive multimedia from Westminster University, London, and the Ph.D. degree in computer science from Southampton University, U.K. She is currently an associate professor with the Faculty of Computer Science and Information Technology, University of Malaya, Malaysia. She has authored or co-authored over 60 refereed publications in international journals, book chapters, and conferences. She has supervised several Ph.D and master's students in the University of Malaya. She also co-supervised several master by research students in the Moratuwa University of Sri Lanka. Her research interest is in personalized and adaptive learning, recommender system, decision support system, big data analytics, and content-based image/video retrieval. She serves as a reviewer for several ISI-indexed journals.

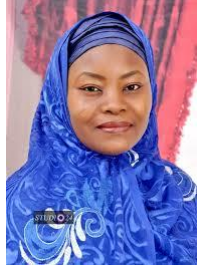

systems.

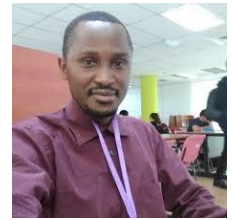

Habeebah Adamu Kakudi received the B.Tech. degree in mathematics and computer science from the Federal University of Technology, Minna, Nigeria, in 1998; and the M.Sc. degree in computer science from Bayero University, Kano, Nigeria, in 2011; the Ph.D. degree with the University of Malaya. She is now a lecturer with Bayero University. Her current research interests include disease prediction, soft computing, evolutionary computing, machine learning, and automated healthcare

Auwal Shehu Ali received the B.Sc. in computer science from Bayero University Kano, Nigeria in 2008; the M.Sc. in computer science from Bayero University Kano and he is currently pursuing his $\mathrm{PhD}$ in University Sains Malaysia. His research interests include front end systems internet of Things and computer security. 